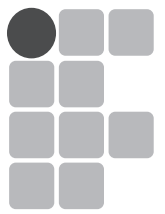

\title{
Correlação do COT e porosidade em Latossolo com diferentes usos e manejos na região de Uberaba, MG
}

\author{
Fernanda Pereira Martins ${ }^{1}$ \\ Risely Ferraz Almeida \\ Joseph Elias Rodrigues Mikhael ${ }^{3}$ \\ Isabel Dayane de Sousa Queiroz ${ }^{4}$ \\ Welldy Gonçalves Teixeira 5 \\ Elias Nascentes Borges ${ }^{6}$
}

\section{Resumo}

O cerrado é o segundo maior bioma brasileiro. Antes do Programa de Desenvolvimento dos Cerrados (POLOCENTRO) e do Programa de Cooperação Nipo-Brasileira de Desenvolvimento dos Cerrados (PRODECER), os solos do cerrado não eram tão cultivados, apresentando menor valor econômico em relação a outras regiões no Brasil. Assim, objetivou-se quantificar as modificações impostas sobre a densidade, a porosidade e o teor de carbono orgânico, em áreas de cerrado, eucalipto e de plantio direto com rotação de milho e de pastagem, em um Latossolo Amarelo no município de Uberaba, MG. Foram coletadas, nas camadas de 0,0 - 20 e 20 - $40 \mathrm{~cm}$, amostras deformadas para determinação do carbono orgânico do solo (COT), análises química e granulométrica, além de amostras indeformadas para as análises de densidade do solo (Ds), microporosidade (Mi), macroporosidade (Ma) e porosidade total (Pt). Constatou-se maior teor de COT na profundidade de 0 a $20 \mathrm{~cm}$. Em relação ao uso, o COT foi maior na área de milho em relação à área de cerrado. A Ds foi maior na camada de 0 a $20 \mathrm{~cm}$ e nas áreas ocupadas por pastagem e milho. Quanto à Ma, Mi e Pt, as áreas ocupadas por cerrado e eucalipto apresentaram resultados semelhantes, mostrando que, na ausência da interferência antrópica, o sistema é capaz de se reestabelecer. As áreas de pastagem e milho apresentaram médias semelhantes, respectivamente, 0,$11 ; 0,30$ e 0,41; 0,07; 0,30 e 0,41. Para a Ma, Mi e Pt, as médias apresentadas foram 0,07; 0,30 e 0,41, ficando, pois, abaixo do ideal.

Palavras-chave: Pastagem. Milho. Eucalipto. Plantio direto.

$1 \quad$ Universidade Federal de Uberlândia, Aluna de doutorado. Belo Horizonte,Minas Gerais e Brasil. martinsgeo@hotmail.com.br. +55 31 75884823. Av. Pres. Antônio Carlos, 6627 - Pampulha, CEP: 31270-901, Belo Horizonte - MG, Brasil.

2 Doutoramento na Universidade Estadual Paulista “Júlio de Mesquita Filho" -UNESP, campus Jaboticabal/SP;Brasil. rizely@gmail. com. + 5516 3209-2600. Via de Acesso Prof. ${ }^{\circ}$ Paulo Donato Castellane, s/n, CEP: 14.884-900, Jaboticabal, SP, Brasil.

3 Louisiana State University. Doutorando ou estudante de PhD (Graduate student). Baton Rouge, Louisiana, Estados Unidos (United States). josephmikhael@hotmail.com .+1 (225) 371-3961. 3964 Gourrier Avenue, ap 332, Baton Rouge, Louisiana, 70808.

4 Centro de Ensino Superior de São Gotardo, Professora. São Gotardo, MG, Brasil. isabeldsq@gmail.com +55 $349110-8374$ Av. Francisco Rezende Filho, 35, Bairro Boa Esperança, São Gotardo/MG, CEP: 38800-000.

5 Doutoranda em Solos e Nutrição de Plantas, Departamento de Solos, Universidade Federal de Viçosa - UFV, Viçosa, MG, wellteixeira@hotmail.com (31) 9171-1358, Av. P. H. Rolfs s/n, CEP 36571-000 Viçosa-MG.

6 Professor da Pós-Graduação em Agronomia, Instituto de Ciências Agrárias - ICIAG, Universidade Federal de Uberlândia. elias@ufu. br. +55 34 3225-8444 Avenida Amazonas s/no - Bloco 2E Sala 01 - Bairro Umuarama, Uberlândia/MG - CEP 38400-902. 


\section{Introdução}

O cerrado é o segundo maior bioma brasileiro e ocupa, aproximadamente, $21 \%$ do território nacional, ou seja, 200 milhões de hectares, superado em área apenas pela Amazônia (BORLAUG, 2002). Antes do programa de desenvolvimento dos Cerrados (POLOCENTRO) e do Programa de cooperação Nipo-Brasileira de desenvolvimento dos Cerrados (PRODECER), os solos do cerrado não eram tão cultivados, apresentando um menor valor econômico em relação a outras regiões no Brasil (SILVA, 2000). Acredita-se que mais da metade da área que compõe esse bioma, nos últimos 35 anos, foi transformada em pastagens, áreas de agricultura, principalmente milho, soja e grandes culturas como o eucalipto e outros usos antrópicos (KLINK; MACHADO, 2006).

Os cultivos com maior movimentação do solo e utilização de fertilizações intensivas apresentam maior vulnerabilidade à compactação do solo (SILVA; MIELNICZUK, 1998; BLANCO-CANQUI et al., 2009;), maior densidade e alterações no volume e distribuição por tamanho dos poros (NETTO et al., 2009). Isso está diretamente relacionado com a dinâmica da água, ar, nutrientes e desenvolvimento de raízes (NETTO et al., 2009), além dos teores de carbono orgânico (STONE; SILVEIRA, 2001). Essas alterações podem influenciar na sustentabilidade e produtividade dos ecossistemas agrícolas por meio da degradação da qualidade ambiental (PAGLIAI et al., 2004).

Em busca da sustentabilidade do setor agropecuário, tem-se a necessidade de manejos que preservem o solo (BERTOL et al., 2004). O Sistema Santa Fé é um exemplo, caracterizado por meio da produção consorciada de culturas de grãos, especialmente o milho, sorgo, milheto e soja, com forrageiras tropicais, principalmente as do gênero Brachiaria, tanto no sistema de plantio direto como no convencional, em áreas de lavoura, com solo devidamente corrigido (KLUTHCOUSKI et al., 2000). Além desse sistema, também se pode citar o sistema de Integração Lavoura Pecuária - iLP, que tem o mesmo princípio, no entanto, com a utilização de pastagens consorciadas com espécies florestais, sendo as do gênero Eucalyptus, seguido da Acácia, as mais utilizadas. Observa-se que o eucalipto é uma espécie exótica e, atualmente, a mais plantada no Brasil (FERNANDES et al., 2010).

Assim, objetivou-se quantificar as modificações impostas sobre a densidade, a porosidade e o teor de carbono orgânico, em áreas de cerrado, eucalipto e de plantio direto com rotação de milho e pastagem, em um Latossolo Amarelo, no município de Uberaba, MG.

\section{Material e Métodos}

O trabalho foi realizado na Fazenda Santa Terezinha (latitude $19^{\circ} \mathrm{S}$ e longitude $48^{\circ} \mathrm{W}$ ), localizada no município de Uberaba, MG, região do Triângulo Mineiro, que apresenta altitude média de 830 m e clima do tipo Aw, segundo a classificação de Köppen, caracterizado como tropical chuvoso, com inverno seco (ANTUNES, 1986). O solo é classificado como Latossolo Amarelo e apresenta textura franco-arenosa (Tabela 1), com teores de argila variando de 16 a 29\% (EMBRAPA, 2006). 
Tabela 1 Características físicas e químicas de um Latossolo Amarelo sob quatro manejos e uso do solo na região de Uberaba, MG.

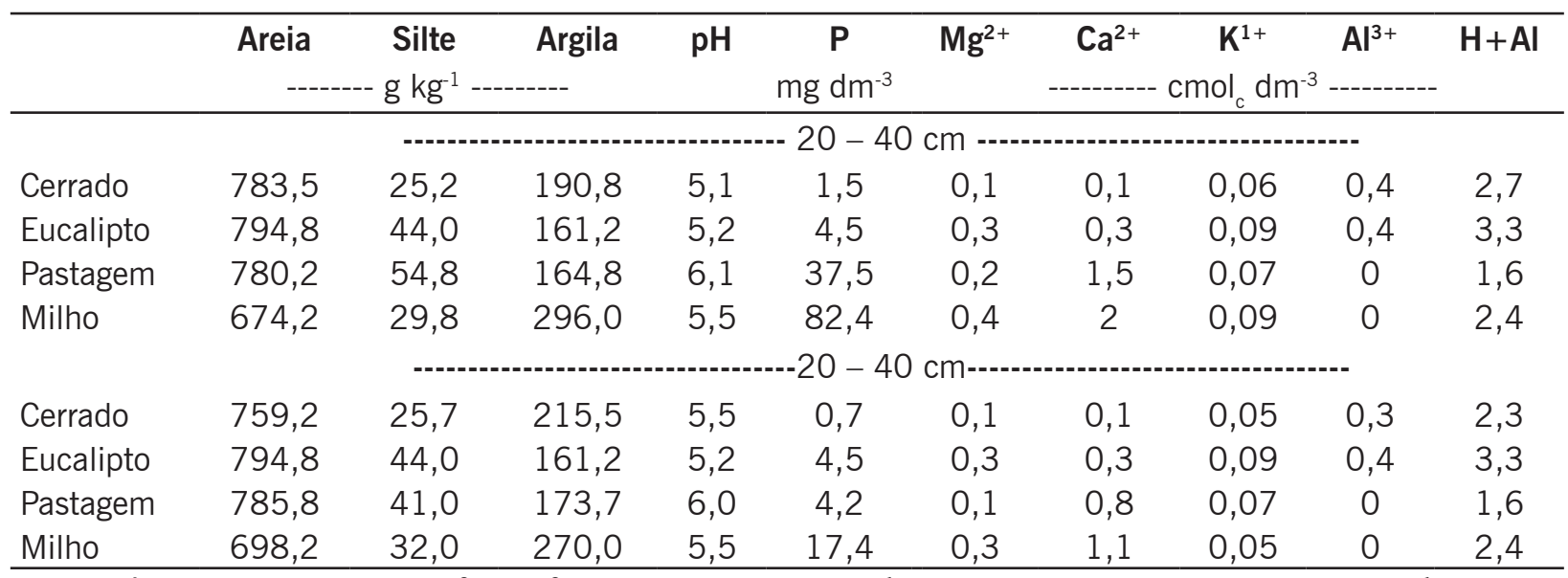

$\mathrm{pH}$ em água, relação 1:2,5. $\mathrm{Ca}^{2+}$ e $\mathrm{Al}^{3+}$ : extrator $\mathrm{KCl} 1 \mathrm{~mol} \mathrm{~L}^{-1} . \mathrm{H}+\mathrm{Al}$ : extrator $\mathrm{Ca}(\mathrm{OAc})_{2}$ 0,5 $\mathrm{mol} \mathrm{L}^{-1} \mathrm{pH}$ 7,0. $\mathrm{P}$ e K: extrator Mehlich-1.

Fonte: Elaboração dos autores.

Foram selecionadas quatro áreas com diferentes usos: Cerrado nativo: vegetação típica de cerrado "strictu sensu", sem histórico de interferência humana, preservado há mais de 30 anos; Eucalipto: floresta plantada há trinta anos, sem manejo de fertilidade desde o período de implantação; Milho: cultivado em sistema de plantio direto (SPD), consorciado com pastagem, de acordo com o sistema de cultivo Santa Fé - SSF (KLUTHCOUSKI et al., 2000); Pastagem: área predominantemente com Brachiaria brizantha, fertilizada anualmente com cama de peru, mas sem controle da quantidade e da qualidade do material adicionado.

A pastagem é conduzida, na mesma área, por cinco anos. Após esse período, a área recebe a cultura do milho por um ano e, novamente, a pastagem é estabelecida e mantida por mais cinco anos.

\section{Variáveis Analisadas}

Para a caracterização química e física (Tabela 1), foram coletadas quatro amostras nas camadas de 0 a 20 e 20 a $40 \mathrm{~cm}$ de profundidade, em quatro pontos distribuídos ao acaso. Em cada ponto, coletou-se uma amostra com estrutura indeformada, utilizando-se anel volumétrico de Kopeck e amostrador tipo Uland, totalizando 16 amostras em cada profundidade. Após a coleta, as amostras foram envolvidas em tela de tecido e encaminhadas ao laboratório para determinação da densidade do solo (Ds), macroporosidade (Ma), microporosidade (Mi) e porosidade total (Pt).

Em laboratório, após a retirada do excesso de solo das bordas dos anéis, as amostras indeformadas foram saturadas com água, por meio da elevação da lâmina de água em uma bandeja, até atingir dois terços da altura do anel. Em seguida, as amostras foram pesadas e levadas para mesa de tensão, regulada para exercer força de sucção sobre as amostras equivalente a de uma coluna de água de 60 $\mathrm{cm}$. Cessada a drenagem da água dos macroporos (poros maiores que 0,05 mm), as amostras foram novamente pesadas e levadas para secagem em estufa com circulação forçada de ar a $105^{\circ} \mathrm{C}$, por 24 $\mathrm{h}$, e novamente pesadas para determinar a microporosidade (poros menores que 0,05 mm).

A porosidade total foi obtida pela diferença entre o peso da amostra após a secagem em estufa e o peso da amostra saturada (EMBRAPA, 1997; WENDLING et al., 2012). Já a densidade do solo 
(Ds) foi calculada como a relação entre o peso da amostra seca em estufa e o volume do anel (EMBRAPA, 1997). Para o carbono orgânico total (COT), fez-se a determinação pela oxidação da matéria orgânica com $\mathrm{K}_{2} \mathrm{Cr}_{2} \mathrm{O}_{7}$ em meio ácido, e o excesso de dicromato foi titulado com $\left(\mathrm{NH}_{4}\right)_{2} \mathrm{Fe}\left(\mathrm{SO}_{4}\right)_{2}$, assim como descrito por Yeomans e Bremner (1988).

A classificação textural foi obtida com o método da pipeta, conforme Embrapa (1997). O pH foi determinado em suspensão solo/água na relação 1:2,5. Na determinação de $\mathrm{P}, \mathrm{K}, \mathrm{Ca}, \mathrm{Mg}$, acidez potencial $(\mathrm{H}+\mathrm{Al})$, utilizou-se o método descrito por Tedesco et al. (1995), enquanto o nitrogênio total foi determinado utilizando-se destilador de arraste a vapor semimicro Kjeldahl (BLACK, 1965)

\section{Análises estatísticas}

Os resultados foram submetidos aos testes de normalidade dos resíduos (Teste de Shapiro-Wilk, SPSS Inc., USA) e de homogeneidade das variâncias (Teste Bartlett, SPSS Inc., USA). Em seguida, quando significativos os resultados (Teste $\mathrm{t}$ ), relacionaram-se as variáveis no esquema de parcelas subdivididas, sendo os sistemas de uso considerados como parcelas e as camadas de solo como subparcelas. Posteriormente, as médias foram comparadas pelo teste de Tukey a 0,05 de probabilidade (Sisvar Inc., Brasil) e correlacionadas pelo teste de correlação linear de Pearson (Sigma-plot In., USA).

\section{Resultados e Discussão}

A análise de variância do teor de carbono orgânico total (COT) não revelou diferenças significativas entre os diferentes usos nas profundidades avaliadas, assim como o teor de COT não diferiu entre as profundidades do solo dentro de cada uso.

No entanto, comparando-se os sistemas de uso, observa-se que a área sob milho cultivado em SSF apresentou o maior teor de COT, diferenciando-se da área do cerrado, onde foram observados os menores valores (Figura 2).

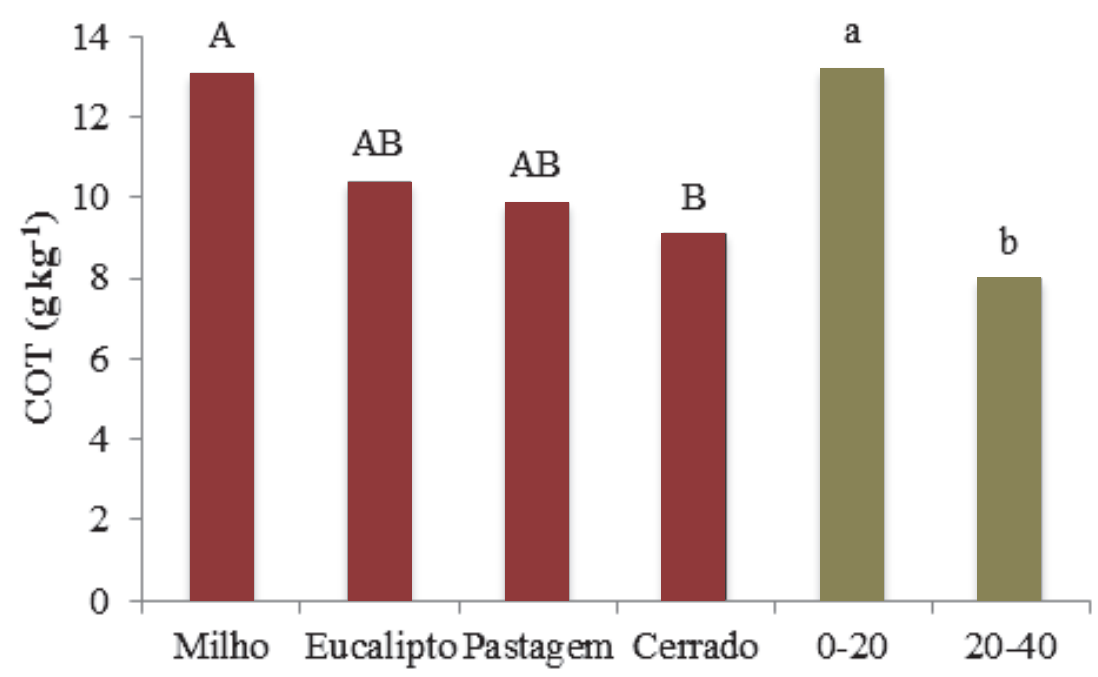

Figura 2 Carbono orgânico total (COT) em áreas com diferentes sistemas de uso e camadas de solo (cm) na região de Uberaba, MG. Barras identificadas com letras iguais, maiúsculas para áreas e minúsculas para profundidades, não diferem entre si pelo teste Tukey a 0,05 de significância.

Fonte: Elaboração dos autores. 
O não revolvimento do solo aliado ao aporte de resíduos da palhada de gramíneas, que é mais lignificada, contribui para a redução da atividade biológica no solo. Assim, a decomposição dos resíduos é mais lenta, promovendo o aumento dos estoques de matéria orgânica no solo. Resultados semelhantes também foram observados em experimentos de longa duração em diferentes regiões do Paraná por Castro Filho et al. (1998) e Sá (1993).

Dentre os usos com agricultura, a área ocupada por pastagem apresenta média de COT menor, uma vez que o aporte de resíduo para o solo é menor. Isso é devido à intensa extração de biomassa vegetal pelo pastejo dos animais (CARDOSO et al., 2010). Além disso, os resíduos provenientes do sistema radicular são rapidamente decompostos pela ação dos microorganismos e pela adubação anual com cama de frango. Mendham et al. (2002) também verificaram menor taxa de decomposição da matéria orgânica do solo em cultivos de eucalipto em comparação à pastagem.

0 teor de carbono orgânico total foi maior na camada de 0 a $20 \mathrm{~cm}$, em relação à camada de 20 a $40 \mathrm{~cm}$ (Figura 2), haja vista a deposição dos resíduos vegetais sobre a superfície e o não revolvimento do solo em nenhum dos sistemas. Essa tendência também foi identificada por Corazza et al (1999) em todos os sistemas por eles estudados, nos quais o acúmulo de COT foi maior na camada superficial e decresceu em maior profundidade. E Kato et al. (2010) verificaram maior teor de carbono orgânico na camada de $0-5 \mathrm{~cm}$ de profundidade do solo, ao avaliarem o efeito de diferentes usos do solo (pastagem, pinus, cerrado e eucalipto).

Houve interação dupla significativa $(P<0,05)$ entre usos e profundidade, para o atributo densidade do solo (Ds). Na camada de 0 a $20 \mathrm{~cm}$, não houve diferença significativa da densidade do solo nos diferentes sistemas de uso, embora a Ds nas áreas de milho e pastagem tenha sido, respectivamente, $6,7 \%$ e 6,3\% maior que as áreas de cerrado e eucalipto, que apresentaram densidade média de $1,5 \mathrm{~g} \mathrm{~cm}^{-3}$ (Figura 3).

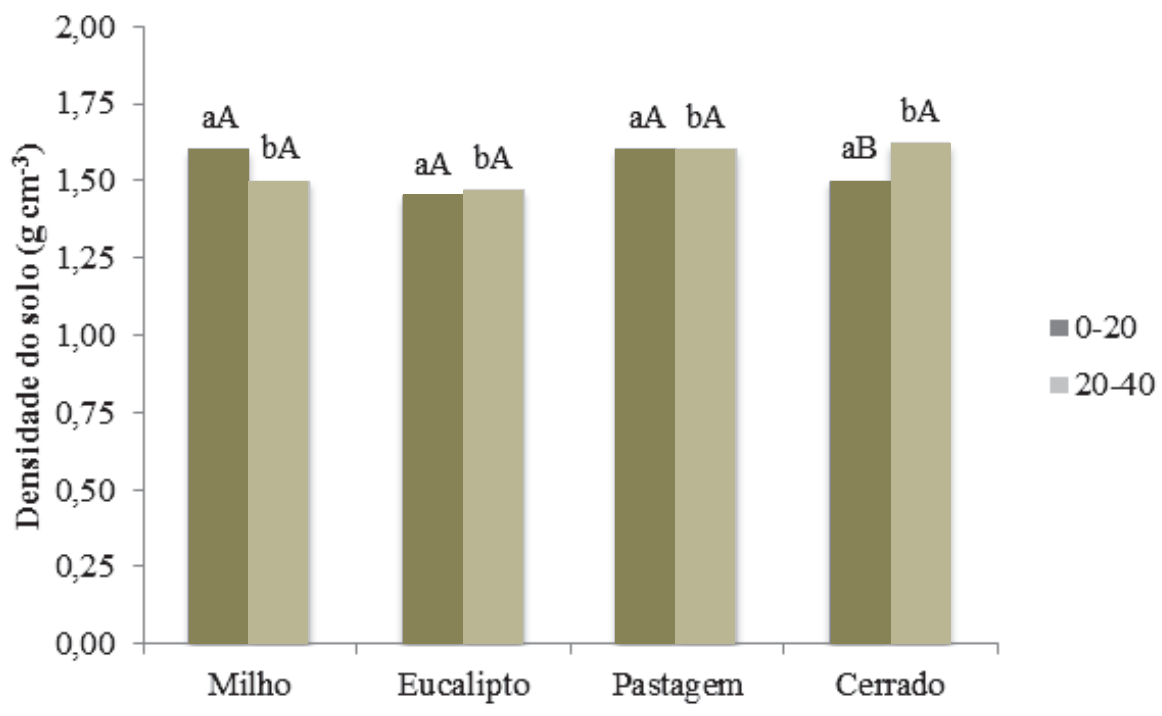

Figura 3 Densidade do solo em áreas com diferentes sistemas de uso e camadas de solo $(\mathrm{cm})$ na região de Uberaba, MG. Barras identificadas com letras minúsculas para usos e maiúsculas para profundidades iguais não diferem entre si pelo teste Tukey a 0,05 de significância.

Fonte: Elaboração dos autores.

Na profundidade de 20 a $40 \mathrm{~cm}$, a densidade do solo nas áreas de milho e eucalipto foi menor que nas áreas de pastagem e cerrado, embora as médias não tenham diferido significativamente. 
Em relação aos usos, não se observou diferença entre as profundidades de 0 a $20 \mathrm{~cm}$ e 20 a $40 \mathrm{~cm}$ para as áreas de milho, eucalipto e pastagem (Figura 3). No entanto, o ambiente cerrado apresentou Ds maior na camada mais profunda, o que pode ser resultado da queda de folhas e galhos, normalmente observada no período seco do ano para as regiões do cerrado.

Para macroporosidade (Ma), não houve interação significativa entre profundidades e usos do solo. No entanto, esse atributo se diferenciou entre os diferentes usos (Tabela 2). A Ma foi maior nas áreas de cerrado e eucalipto, uma vez que, nesses ambientes, está relacionada com o número de raízes de árvores presentes nesses sistemas e, também, à atividade de organismos do solo. Essa atividade biológica permite a formação de pequenos dutos e galerias que contribuem para o aumento no número de macroporos nesses ambientes. Vale ressaltar que a área de eucalipto apresenta resultado semelhante à do cerrado porque há trinta anos não há interferência antrópica naquela área.

Tabela 2 Macroporosidade (Ma), microporosidade (Mi) e porosidade total (Pt) sem efeito de camada em áreas com diferentes sistemas de uso na região de Uberaba, MG ${ }^{1}$.

\begin{tabular}{cccc}
\hline Sistemas de uso & Ma & Mi & Pt \\
\cline { 3 - 3 } & & $\mathrm{g} \mathrm{cm}^{-3}$ & \\
Cerrado & $0,187 \mathrm{~A}$ & $0,28 \mathrm{~A}$ & $0,45 \mathrm{~A}$ \\
Eucalipto & $0,187 \mathrm{~A}$ & $0,28 \mathrm{~A}$ & $0,45 \mathrm{~A}$ \\
Pastagem & $0,112 \mathrm{~B}$ & $0,30 \mathrm{~A}$ & $0,41 \mathrm{~A}$ \\
Milho & $0,075 \mathrm{~B}$ & $0,30 \mathrm{~A}$ & $0,41 \mathrm{~A}$ \\
\hline CV (\%) & 37,71 & 10,4 & 11,0 \\
DMS & 0,064 & 0,058 & 0,099 \\
\hline
\end{tabular}

1 - Variáveis expressas em $\mathrm{dm}^{3} \mathrm{dm}^{-3}$. Na tabela, médias seguidas de letras iguais na coluna não diferem entre si pelo teste Tukey a 0,05 de significância.

Fonte: Elaboração dos autores.

O volume de microporos não diferiu significativamente entre os usos. A porosidade total também não apresentou resultado estatisticamente significativo entre os usos, mas a maior média de Pt ocorreu nos ambientes cerrado e eucalipto (Tabela 2).

Verificou-se uma correlação negativa entre Ma e Mi $\left(r=-0,742^{*}\right)$, uma vez que o aumento da Ma no solo contribuiu para o decréscimo da Mi. Para Ma e Pt, verificou-se uma correlação significativa positiva entre ( $r=0,704)$, com acréscimo conjunto entre as duas variáveis (Tabela 3 ).

Tabela 3 Correlação entre as variáveis, macroporosidade (Ma), microporosidade (Mi), porosidade total (Pt), densidade dos solos (Ds) e carbono orgânico total (COT), com diferentes sistemas de uso na região de Uberaba, MG

\begin{tabular}{ccccc}
\hline & Ma & Mi & Pt & COT \\
\hline Ds & $-0,204$ & 0,161 & $-0,237$ & 0,123 \\
Ma & - & $-0,742^{* *}$ & $0,704^{*}$ & 0,037 \\
Mi & - & - & $-0,059$ & 0,208 \\
Pt & - & - & - & 0,268
\end{tabular}

As variáveis são consideradas significativas com $P<0,050 .{ }^{*}$ Correlações positivas. ** Correlações negativas. Fonte: Elaboração dos autores.

Nas áreas cultivadas com milho e pastagem, observou-se comportamento inverso, ou seja, observou-se maior quantidade de Mi em relação a Ma (Tabela 2). Wendling et al. (2012) também 
encontraram maior quantidade de microporos em ambientes de pastagem e semeadura direta quando comparados com os ambientes cerrado e floresta de Pinus. Oscilações entre essas duas variáveis também foram observadas por Albuquerque et al. (2001) e Bertol et al. (2004), que afirmaram serem os macroporos mais susceptíveis a mudanças impostas pelo manejo do que os microporos.

A elevada microporosidade do solo nas áreas com pastagem e milho demonstra que o tipo de manejo empregado - tanto no sistema antecedido por pastagem, com o pisoteio dos animais, como no sistema de trânsito de maquinário para plantio e colheita do milho - pode levar à compactação do solo. Assim, mesmo em condições de rotação de cultura, o pisoteio animal tende a promover um desarranjo maior na estabilidade dos agregados, favorecendo a individualização das partículas do solo, com o comprometimento da porosidade e diminuição da infiltração e redistribuição de água no solo, acarretando aumento na densidade e reflexos negativos na produção agrícola (JUNIOR et al., 2010).

Todos os usos avaliados, nas duas profundidades, apresentaram volume de macroporos $(0,07$ a $0,18 \mathrm{dm}^{3} \mathrm{dm}^{-3}$ ) abaixo do considerado ideal, 0,33 $\mathrm{dm}^{3} \mathrm{dm}^{-3}$, conforme sugerido por Taylor e Aschcroft (1972), citado por Bertol et al. (2004).

Esse valor seria limitante ao desenvolvimento radicular devido à reduzida taxa de difusão de gases no solo e à dificuldade de drenagem do excesso de água das chuvas (BERTOL et al, 2004).

\section{Conclusões}

O teor de carbono orgânico total é maior na camada superficial do solo, de 0 a $20 \mathrm{~cm}$, e na área ocupada por milho, em sistema de Plantio Santa Fé, quando comparada com a área de cerrado.

A densidade do solo é maior na camada superficial nas áreas ocupadas por pastagem e milho. A área com Cerrado e eucalipto apresentam macro, micro e porosidade total semelhante.

\section{Agradecimentos}

Agradecimentos à FAPEMIG (Fundação de Amparo à Pesquisa do Estado de Minas Gerais) e ao CNPq (Conselho Nacional de Desenvolvimento Científico e Tecnológico). Ao Laboratório de Manejo e Conservação dos Solos, ao Laboratório de Cartografia pela utilização de seus recursos, ao IEF pelas imagens utilizadas neste trabalho e à Fazenda Santa Terezinha.

\section{Correlation of TOC and porosity OXISOL with different uses and management in region of Uberaba, MG}

\section{Abstract}

The Cerrado is the second largest biome. Before the Development of the Cerrado (POLOCENTRO) and the Program for Japanese-Brazilian Cooperation in Developing the Cerrado (PRODECER) program, the Cerrado soils were not as grown, with less economic value compared to other regions in Brazil. The objective of this study was to quantify the changes imposed on the density, porosity and organic carbon content in Cerrado areas, eucalyptus and corn and pasture tillage rotation at Fazenda Santa Therese, Uberaba - MG. Disturbed samples were collected in the layers of 0-20 cm and 20-40 $\mathrm{cm}$ for soil organic carbon (TOC) determination and analyzes of chemical and particle size, and the undisturbed samples for analyzes of soil density (Ds), microporosity (Mi), macroporosity (Ma) and to- 
tal porosity (Pt). It was found that there was higher TOC content in the depth of 0 to $20 \mathrm{~cm}$. Relative to the use of the soil, the corn area's TOC was higher in relation to the TOC of the Cerrado area. DS was higher in the depth of 0 to $20 \mathrm{~cm}$ and in the areas occupied by pasture and corn. For Ma, Mi and $\mathrm{Pt}$, the areas occupied by cerrado and eucalyptus had similar results, showing that in the absence of human interference the system is able to reestablish. The pastures and corn showed similar average for $\mathrm{Ma}$, Mi and Pt, respectively, $0.11 ; 0.30$ and $0.41 ; 0.07 ; 0.30$ and 0.41 . However, these were less than ideal.

Keywords: Pasture. Corn. Eucalyptus. No tillage.

\section{Referências}

ALBUQUERQUE, J. A.; SANGOI, L.; ENDER, M. Efeitos da Integração Lavoura-Pecuária nas propriedades Físicas do Solo e características da Cultura do Milho. Revista Brasileira de Ciência do Solo, v.25, p.717-723. 2001.

ANTUNES, F. Z. Caracterização climática do Estado de Minas Gerais. Informe Agropecuário, Belo Horizonte, n.138, p.9-13p. 1986.

BLACK, C.A. Methods of Soil Analisys: Part 2 - Chemical and Microbiological Properties. Madison: American Society of Agronomy, 1159p. 1965.

BORLAUG, N. E. Feeding a world of 10 billion people: the miracle ahead. In: R. Bailey (Ed.). Global warming and other eco-myths. Competitive Enterprise Institute, Roseville, EUA. p. 29-60, 2002.

BERTOL, I; AlBUqUeRQUE, J. A.; LeITE, D.; AMARAL, A. J.; ZOLDAN JR., W. A. Propriedades físicas do solo sob preparo convencional e semeadura direta em rotação e sucessão de culturas, comparadas às do campo nativo. Revista Brasileira de Ciência do Solo, Viçosa, v.28, p.155-163. 2004.

BLANCO-CANQUI, H.; STONE, L. R.; SCHLEGEL, A. J.; LYON, D. J.; VIGIL, M. F.; MIKHA, M. M.; STAHLMAN, P. W.; RICE, C. W. No-till induced increase in organic carbon reduces maximum bulk density of soils. Soil Science Society of America Journal, v.73, p.1871-1879. 2009.

CASTRO FILHO, C.; MUZILLI, O; PODANOSCHI, A. L. Estabilidade dos agregados e sua relação com o teor de carbono orgânico num LATOSSOLO roxo distrófico, em função de sistemas de plantio, rotações de culturas e métodos de preparo das amostras. Revista Brasileira de Ciência do Solo, Viçosa, v.22, p.527-538. 1998.

CARDOSO, E. L.; SILVA, M. L. N.; SILVA, C. A.; CURI, N.; FREITAS, D. A. F. Estoques de carbono e nitrogênio em solo sob florestas nativas e pastagens no bioma Pantanal. Pesquisa Agropecuária Brasileira, Brasília, v.45, n.9, p.1028-1035. 2010.

CORAZZA, E. J; SILVA, J. E. D; RESCK, D. V. S.; GOMES, A. C..Comportamento de diferentes sistemas de manejo como fonte ou depósito de carbono em relação à vegetação de Cerrado. Revista Brasileira de Ciência do Solo, Viçosa, v.23, p.425-432. 1999.

EMBRAPA. Empresa Brasileira de Pesquisa Agropecuária. Sistema Brasileiro de classificação de Solos. 2.ed. Rio de Janeiro, Embrapa, 2006. 412p. 
EMBRAPA. Empresa Brasileira de Pesquisa Agropecuária. Manual de Métodos de Análise de Solo. 2.ed. Rio de Janeiro, 1997. 212 p.

FERNANDES, P. C. C.; CHAVES, S.S.F.; FREITAS, D.R.; SILVA, A. V.; SILVEIRA FILHO, A. Consolidação das pesquisas em integração lavoura-pecuária-floresta no Brasil. In: WORKSHOP INTEGRAÇÃO LAVOURA-PECUÁRIA-FLORESTA EM PORTO VELHO. 2010, Porto Velho. Resumos expandidos... Porto Velho: Embrapa Rondônia, 2010.

JUNIOR, H. B. M.; DUARTE, I. N.; BENEDETTI, M. M.; BORGES, E. N. Atributos Físicos de um Latossolo sob Diferentes Sistemas de Manejo. Enciclopédia Biosfera, Centro Científico Conhecer, Goiânia, v.6, n.11, p.1-14. 2010.

KATO, E; RAMOS, M. L. G.; VIEIRA, D. F. A.; MEIRA, A. D.; MOURÃO, V. C. Propriedades físicas e teor de carbono orgânico de um latossolo vermelho-amarelo do cerrado, sob diferentes coberturas vegetais. Bioscience Journal, Uberlândia, v.26, p.732-738. 2010.

KLUTHCOUSKI, J; COBUCCI, T.; AIDAR, H.; YOKOYAMA, L. H.; OLIVEIRA, I. P.; COSTA, J. L.; SILVA, J. G.; VILELA, L.; BARCELLOS, A. O.; MAGNABOSCO, C. U. Sistema Santa Fé - Tecnologia EMBRA$\mathrm{PA}$ : Integração lavoura - pecuária pelo consórcio de culturas anuais com forrageiras, em áreas de lavoura, nos sistemas plantio direto e convencional. Embrapa Arroz e Feijão, - (Circular Técnica / Embrapa Arroz e Feijão), 28 p., 2000.

MENDHAM, D. S.; O'CONNELL, M.; GROVE, T. S. Organic matter characteristics under native forest, longterm pasture, and recent conversion to eucalyptus plantations in Western Australia: microbial biomass, soil respiration, and permanganate oxidation. Australian Journal of Soil Research,v.40, n.5, p.859-872. 2002.

NETTO, I. T. P.; KATO, E; GOEDERT, W. J. Atributos físicos e químicos de um latossolo vermelho-amarelo sob pastagens com diferentes históricos de uso. Revista Brasileira de Ciência do Solo,Viçosa, v.33,1441-1448. 2009.

PAGLIAI, M.; VIGNOZZI, N.; PELLEGRINI, S. Soil structure and the effect of management pratices. Soil Tillage Reschard, v.79, p.131-143. 2004.

KLINK, C. A; MACHADO, R. B. Conservation of the Brazilian Cerrado. Conservation Biology. v.19, n.3, p.707-713.2006.

SÁ, J. C. M. Manejo da fertilidade do solo no plantio direto. Castro: FUNDAÇÃO ABC, 1993. 96p.

STONE, L. F.; SILVEIRA, P. M. Efeitos do sistema de preparo e da rotação de culturas na porosidade e densidade do solo. Revista Brasileira de Ciência do Solo, Viçosa, v.25, p.395-401. 2001.

SILVA, L. L. O Papel do Estado no processo de ocupação das áreas de cerrado entre as décadas de 60 e 80. Caminhos da Geografia. Uberlândia, v.2, p.24-36, 2000.

SILVA, I. F.; MIELNICZUK, J. Sistemas de cultivo e características do solo afetando a estabilidade de agregados. Revista Brasileira de Ciência do Solo, Viçosa, v.22, n.2, p.311-317, 1998.

TEDESCO, M. J.; BOHNEM, H.; GIANELLO, C.; BISSANI, C. A.; VOLKWEISS, S. J. Análise de solo, plantas e outros materiais. 2.ed. Porto Alegre, Universidade Federal do Rio Grande do Sul, 174 p. (Boletim Técnico, 5). 
WENDLING, B.; FREITAS, I. C. V.; OLIVEIRA, R. C.; BABATA, M. M.; BORGES, E. N. Densidade, agregação e porosidade do solo em áreas de Conversão do cerrado em floresta de pinus, pastagem e Plantio direto. Bioscience Journal, Uberlândia, v.28, p.256-265, 2012.

\section{Histórico}

Submetido em: 26/11/2013

Aceito em: 30/09/2014 